\title{
NAMES, VARIETIES AND IDEOLOGIES IN REVIVED CORNISH
}

\author{
MERRYN DAVIES-DEACON
}

Queen's University Belfast

\begin{abstract}
The attribution of names is a significant process that often highlights concerns over identity, ideology and ownership. Within the fields of minority languages and Celtic Studies, such concerns are especially pertinent given that the identities in question are frequently perceived as under threat from dominant cultures. The effect of concerns caused by this can be examined with reference to revived Cornish, which became divided into three major varieties in the later twentieth century; by examining the names of these varieties, we can draw conclusions about how they are perceived, or we are invited to perceive them. The motivations of those involved in the Cornish language revival are equally reflected in the names of the organisations and bodies they have formed, which equally contribute to the legitimation of revived Cornish. This paper examines both these categories of name, as well as the phenomenon of Kernowisation, a term coined by Harasta (2013) to refer to the adoption of Cornish personal names, and here extended to the use of Cornish names in otherwise English-language contexts.

Examining the names that have been implemented during the Cornish language revival, and the ways in which they are used or indeed refused by those involved, gives us an insight into the various ideologies that steer the revival process. Within the context of the precarious nature of Cornish and Celtic identity, we can identify the concerns of those involved in the Cornish revival movement and highlight the role of naming as an activity of legitimation, showing how the diversity of names that occur reflects an equally diverse range of motivations and influences.
\end{abstract}

Keywords: Cornish, language varieties, legitimacy, identity, language revival

\section{Introduction}

Naming a concept is an act that establishes its identity. In anthropology, personal names, 
while associated with an individual, are laden with social history and power, and they are easily manipulated in the hands of others. Across societies, people carefully control the way names are used, who uses them, and in what context. A proper name, then, is not simply a useful label, but a repository of accumulated meanings, practices, and beliefs, a powerful linguistic means of asserting identity (or defining someone else) and inhabiting a social world (Rymes 1999:165).

As names "index familiarity, kinship, and group membership" (Rymes 1996: 242), the act of naming is a way of displaying these attributes, indicating which particular community ties are perceived as most salient in the construction of the named individual's identity. Place names, too, are endowed with similar meaningful properties, allowing them to become sites of ideological battle: examples include the case of Derry/Londonderry, where the two coexisting names indicate different political alignments. Recent work on postcolonial contexts has highlighted a trend among governments to allow the removal of colonially imposed place names in favour of indigenous replacements; however, when the new name is not linked to existing cultural traditions, this "runs the risk of being a shallow and meaningless activity that misappropriates [indigenous] language and culture" (Amery and Yambo Williams 2009: 267). Nonetheless, when granting names that are deemed appropriate by the community, such naming processes constitute "a performative enactment of indigenous ways of knowing and being with the land" (Rose-Redwood 2016: 191), again demonstrating the way in which the naming process asserts identity and membership of a particular group. As similar motivations behind naming practices can be found among both personal names and place names, we can expect to make similar observations when considering names more widely, including those given to concepts, organisations, and ideas.

Within the field of Celtic Studies in particular, the issue of names and identities is especially pertinent. The definition of Celt or Celtic is the subject of longstanding debate, to which various solutions have been proposed over time; some have suggested that the word Celt(ic) should not be used at all. This "academic controversy" (Koch 2003: 43) stems from concerns over the validity of the Iron Age Celt:

One strand of the debate about the Celts today seems to be that if these Iron Age people did not all call themselves 'Celts', if they did not all use La Tène culture, or the same sort of La Tène culture, if the speaker of one of these languages in Ireland was not aware of the existence of similar languages in Spain and Turkey, then it is not permissible for us to identify them as 'Celts' (Koch 2003: 42). 
As a result, 'Celtosceptics' argue, the name Celt(ic) should not be used in reference to these Iron Age peoples. If there is no basis for grouping these cultures together, there is no need for a name; conversely, denied the name, it is impossible to conceptualise a coherent group. This 'Celtoscepticism' can be extended to a modern context: with no political and little historical unity among the areas typically grouped together as Celtic, nor a linguistic definition that includes the entirety of the relevant territories, ${ }^{1}$ the concept of contemporary Celtic identity is fragile.

\section{The Cornish context}

In modern Cornwall, the uncertainty over the legitimacy of the Celt is augmented by an uncertainty over the legitimacy of Cornish identity. Unlike the other 'Celtic' parts of the UK, Cornwall benefits from no devolved parliament and is typically characterised as an English county. The 'national minority' status granted to the Cornish in 2014 appears to have had no tangible effect, as shown by the British government's current plans to merge parts of Cornwall and neighbouring Devon into the same parliamentary constituency. This lesser degree of recognition, coupled with the more precarious status of their language, means that the Cornish are forced to question their own identity: are they a distinct people? Do they count as Celtic? This particular fragility of the Cornish identity in comparison with its wider Celtic context has been identified by Neil Kennedy, who claims that

Cornwall is not part of the larger territory. There are no nearby areas of Celtic speech or further Llŷn Peninsula to conform more closely to the model, nor is Cornwall redeemed by national institutions and a critical mass of population. The Cornish are consequently slightly suspect, Cinderella Celts, ranked in fifth or sixth place (Kennedy 2013: 136).

The Cornish language revival, a major site for the expression of contemporary Cornish identity, is thus forced to deal with such uncertainties: those involved in the movement must establish Cornish as sufficiently Celtic for it to deserve its place among the other Celtic languages undergoing revitalisation, as well as within the academic discipline of Celtic Studies. Names and the act of naming are critical for this assertion of identity. This paper will accordingly examine the ways in which names have been used in the Cornish language revival in order to situate and legitimate Cornish identity, investigating three categories of names.

For example, Breton has not been spoken in eastern parts of Brittany since the ninth century. The effects of more recent language shift also show that it is insufficient to claim that Celticity is restricted to areas where Celtic languages are spoken, as this definition would now exclude certain areas of Ireland, Wales and Scotland. 


\section{Names for varieties of Cornish}

As is common in cases of language revival and revitalisation, the revival of Cornish, now of more than a century's standing ${ }^{2}$, has seen much debate over the merits of different varieties and the selection of a standard language. While a particularly salient issue within the revival movement, the details of this have been subject to little academic criticism. Earlier studies of the Cornish language revival, such as Wakelin (1975) and Price (1984), are able to reject the validity of revived Cornish entirely, highlighting its apparently inauthentic quality due to the cessation of intergenerational transmission prior to the beginning of the revival. More recent advances in sociolinguistics have enabled more thorough criticism of revived languages on their own terms, rather than insisting on placing them in the shadow of the prestige of traditional varieties. However, much recent work on Cornish from a sociolinguistic perspective, often produced by researchers from outside the Cornish language community and with restricted access to the nuances of the debates that took place in the 1990s and 2000s, is uncritical of contemporary language planning, presenting the development of the so-called Standard Written Form of Cornish (SWF) as a neat solution to disagreement (e.g. Sayers 2012, Ferdinand 2013) and implying that other varieties and orthographies can now be put aside ${ }^{3}$. This work is in danger of neglecting the fact that the Cornish language community draws on different and sometimes conflicting ideologies whose coexistence makes the possibility of standardising the language in a way that satisfies the whole community highly unlikely. This paper shows some of the ways in which the use of names has highlighted these various ideologies, both within the context of the orthography debate and since the uneasy truce brought about by the development of the SWF.

With the written corpus of traditional Cornish the major source for reconstructing the language, and the sole source for certain varieties, gaps have had to be filled and inconsistencies smoothed over: different groups have gone about this in different ways, drawing different conclusions about the linguistic features of Cornish and relying on different sources as aids in carrying out this reconstruction. As a result, multiple varieties of revived Cornish emerged during the twentieth century. The diagram below shows the major varieties of revived Cornish, providing a simplified overview of which varieties influenced the creation of others.

2 The beginning of the Cornish language revival is typically dated to the publication of Henry Jenner's $A$ handbook of the Cornish language in 1904.

3 The continued presence of the varieties focused on in this paper, and their derivatives, both online and in published texts, shows that this is not the case; the SWF was implemented nearly a decade ago. 


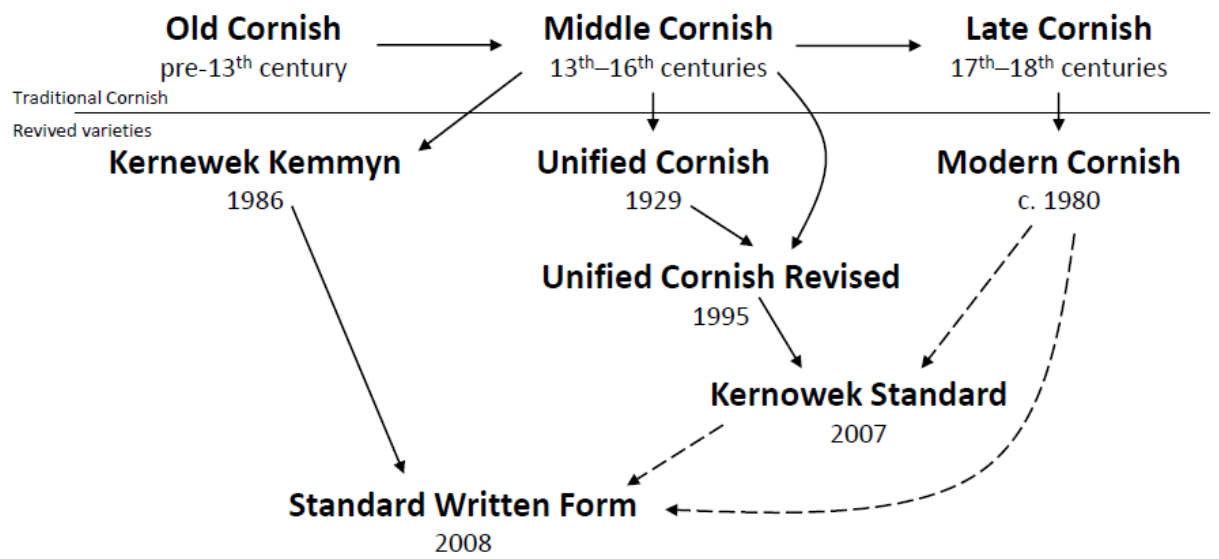

Figure 1: Varieties of Cornish

\subsection{Unified Cornish}

The first such variety to achieve widespread use within the context of the Cornish language revival was created by Robert Morton Nance in the early twentieth century; it is now known as Unified Cornish. At its creation, however, it was referred to as a unified spelling:

To make the Cornish of this book as useful as possible to beginners it is therefore all put back [sic] into a 'unified' spelling that is based on the Cornish of the three days' plays of the Ordinal ('Prompt-Book'), the accepted model of Cornish at its best (Nance 1929: 6).

Nance's use of this term shows that originally, unified referred merely to the orthography of Cornish rather than to an entire linguistic system. Later, however, its frame of reference would expand. Nance would later use the phrase Middle Cornish in unified form (Nance 1952: vii), implying that a discrete variety of Cornish was now under discussion, including grammatical and lexical elements rather than existing merely as an orthographic system. This term, however, is still a multiple-word description rather than a name; indeed, at this point there was still no name for this specific variety of Cornish.

By the 1970s, however, the term Unified Cornish (Combellack 1978: 46) had come into widespread use among Cornish revivalists. The brevity of this description, and its inclusion of a capital $U$ on Unified, indicate that by this point it had become a name. Nance's variety had thus, finally, gained a name, and with it, a particular identity as a specific type of Cornish, a conservative, 
'classical' variety based on a regularised form of the language of fourteenthcentury texts. Over the intervening decades, the name Unified had also gained an established parallel in the dominant orthography for Breton since the 1940s, called peurunvan 'supraunified'.

While this conceptualisation of Unified Cornish as a distinct variety strengthened the coherence of its identity, its framing as a subset of the Cornish language also created space for potential alternative subsets to be proposed in its stead. Indeed, it was also in the 1970s that doubts about the validity of Unified Cornish began to arise, paving the way for 'rival' varieties to be created and promoted.

\subsection{Kernewek Kemmyn}

One such 'rival' variety to meet widespread success among Cornish speakers was devised by Ken George in the mid-1980s. Like Unified Cornish, it originally had no name, and was referred to, somewhat wordily, as a "recommended phonemic spelling"4. George (1986: 96) noted that "it may be desirable to refer to it by some shorter name, but so far, I have not devised one". By the time of the publication of the first dictionary to use this variety (George 1993), a shorter name had indeed been devised: Kernewek Kemmyn 'Common Cornish'.

Reasons behind the attribution of this name are easy to identify. The use of the word common appeals to potential learners, suggesting that Kernewek Kemmyn is a comfortingly normal, everyday type of Cornish, an antidote to the more formal style associated with Unified Cornish. Attracting learners of course was, and still is, a major concern for the Cornish revival movement.

It is worth noting, however, that this name is at odds with the way in which Kernewek Kemmyn was perceived at its introduction. Visually, in terms of its orthography, Kernewek Kemmyn was strikingly different from the Unified Cornish that speakers were accustomed to; while Unified Cornish was based on the orthography of traditional Cornish, which was itself not greatly dissimilar to that of English, and so not particularly alien in appearance to readers, Kernewek Kemmyn broke with this tradition, respelling the language based on a reconstruction of Middle Cornish phonology and employing new diagraphs not found in Unified Cornish or in English, such as $\langle\mathrm{hw}\rangle,<\mathrm{eu}>$ and $\langle\mathrm{tj}\rangle^{5}$. The name Common Cornish can be read as an attempt to counter speakers' concerns that "an lytherennans noweth yu coynt y semblant, estranj dhe weles" [the new orthography is odd in

$4 \quad$ While this suggests that Kernewek Kemmyn deviates from Unified Cornish in purely orthographic terms, it does in fact also entail significant phonological differences, and several grammatical and lexical differences.

5 The third of these was considered so objectionable that it was later removed from Kernewek Kemmyn, along with its voiced counterpart $<\mathrm{dj}>$. 
appearance, strange to look at] (Brown 1987: 2); to combat this disparity between Kernewek Kemmyn and the de facto norm of Unified Cornish, those who favoured Kernewek Kemmyn sought to transfer the role of norm onto their variety, and were successful in that it came to be 'officially' adopted by the Cornish Language Board, at the time the chief regulatory body for Cornish ${ }^{6}$.

\subsection{Modern Cornish}

The third major variety of Cornish to be developed in the twentieth century was not based on Middle Cornish, as Unified Cornish and Kernewek Kemmyn had been, but instead on seventeenth- and eighteenth-century attestations of the language. It was originally given the name Traditional Cornish, emphasising its connection with longstanding inherited traditions and its linguistic and orthographic proximity to surviving Cornish place names, appealing to potential learners who were already well acquainted with surviving local customs.

Traditional Cornish? That's the Cornish that was spoken by our last native speakers. Many words from Traditional Cornish have survived into Cornish dialect and placenames, and you may already be familiar with some of them (Gendall 1988: 2).

In around 1990, Traditional Cornish was renamed Modern Cornish. Again, this name emphasises the fact that the variety is based on a later form of Cornish than its competitors are, and materials designed to promote it clearly frame this proximity to the present day as an asset, claiming that "so recently, indeed, was Cornish in use, that for Cornish people it is in a very real sense the language of our forefathers who lived and worked in Penwith ${ }^{7}$ where the language survived longest" (Gendall 2000: i). As well as emphasising this long, unbroken tradition, accorded legitimacy through genealogy as suggested by the references to "Cornish people" and "our fathers", the name Modern Cornish also indicated the variety's potential relevance to present-day society. Again, this is an important concern in language revival and revitalisation: proving that the language is relevant helps attract both learners and funding.

Despite the use of this name by supporters of this variety, however, it would be employed only rarely by users of other types of Cornish: we shall return to this in section 6 .

$6 \quad$ As a result, however, "the Cornish Language Board found itself recast as a pressure group advocating one particular form of Revived Cornish" (Payton 2000: 117), and no single nonfactional body held supreme authority over the language revival until the establishment of the Cornish Language Partnership in 2005.

7 The westernmost part of Cornwall, where use of Cornish persisted into the late eighteenth century. 
4. Names for organisations

Names for the organisations involved in the Cornish language revival constitute a second category of name that can equally be examined in order to reveal the concerns operating within the movement. Ken MacKinnon identified several organisations that promoted Cornish in a report on the revival carried out in the year 2000. The following table is adapted from the findings of this report (MacKinnon, 2000: 33-34), augmented with the names of two organisations founded in the years since its publication.

Table 1: Organisations

\begin{tabular}{|l|l|}
\hline Official Cornish name & Official English name \\
\hline Gorseth Kernow/Gorsedh Kernow & Gorsedd of Cornwall \\
\hline Kesva an Taves Kernewek & Cornish Language Board \\
\hline Kowethas an Yeth Kernewek & Cornish Language Fellowship \\
\hline Dalleth & - \\
\hline Agan Tavas & - \\
\hline Cussel an Tavas Kernuack & Cornish Language Council \\
\hline Teer ha Tavas & Land and Language \\
\hline Maga & Cornish Language Office \\
\hline Movyans Skolyow Meythrin & - \\
\hline
\end{tabular}

Three points can be raised from this list of names. Firstly, a number of the English names follow a similar pattern: 'Cornish Language $X$ ', where $X$ is a noun implying some level of official status. Out of the four organisations named using this scheme, only the Cornish Language Office is a truly official body, funded by local government, non-partisan as regards the promotion of specific varieties, and responsible for language planning in official contexts, such as the implementation of bilingual street signage and the promotion of Cornish in schools. To outsiders, it would be difficult to tell which of the groups holds this official position; groups advocating the use of particular varieties thus establish their claim to legitimacy by using official-sounding names, hoping to attract more potential learners to the varieties they support by virtue of this apparently high status.

Secondly, certain names in this list are very similar to the names of Welsh and Breton organisations. The name of Agan Tavas translates to English as 'Our Language', as does the name of long-established Breton-language periodical Hor Yezh. Similarly, a periodical publishing articles relating to the linguistic nature of

8 'Cornish Language Partnership' until summer 2016; this name is still visible in certain materials. 
Cornish exists called Agan Yeth, even closer to the Breton name (although not associated with Agan Tavas). ${ }^{9}$ The organisation Movyans Skolyow Meythrin 'nursery schools movement' clearly bases its name on the Welsh association Mudiad Ysgolion Meithrin ${ }^{10}$, a larger and longer-established organisation with the same purpose, providing nursery school-level immersion in the regional minority language: indeed, the word meythrin is a direct borrowing from Welsh, not found elsewhere in Cornish ${ }^{11}$. Such analogues to Welsh and Breton groups strengthen Cornwall's fragile Celtic identity, emphasising the legitimacy of the language revival by linking it with the stronger movements that promote the revitalisation of the other Brythonic languages.

Thirdly, some of the organisations have no official English names, but only Cornish names; we shall return to this in the following section.

\section{5. 'Kernowisation'}

Harasta (2013: 196) introduces the concept of Kernowisation, using this term to describe the process by which a Cornish speaker adapts his or her name, or replaces it entirely, in order to make it sound more Cornish. This can also be identified in other Celtic languages, including Breton, where numerous wellknown language activists have adapted their names ${ }^{12}$, and Irish, where, among republican prisoners in Northern Ireland, "the development of Irish language versions of personal names was common practice during the period between 1976 and 1981" (Mac Giolla Chríost 2012: 98). For Cornish, Harasta (2013: 197) gives a list of thirteen examples. Many of these involve spelling changes: the Cornish surname Angove, for example, may be replaced with 'An Gof', conforming with contemporary orthography and making the Cornishness of the name more immediately evident. Others entail the replacement of an English forename with its Cornish equivalent: for example, the replacement of the name George with 'Jori' is attested.

Harasta points out that users of Kernewek Kemmyn appear to undertake this process more often than users of other varieties: of his sample of thirteen

$9 \quad$ Yeth and tavas are both used in Cornish to mean 'language'; tavas tends to be used by speakers of Unified Cornish and Modern Cornish, while yeth, a borrowing from Welsh via Breton, is preferred by speakers of Kernewek Kemmyn.

10 Now Mudiad Meithrin.

11 As meithrin means 'nourish', the Cornish word maga, which carries this meaning, might have been better suited, were this not already in use as the Cornish name for the Cornish Language Office.

12 Perhaps most famously, Roparz Hemon (né Louis Némo), an influential Breton linguist and one of the foremost promoters of the peurunvan orthography. 
people, ten are Kernewek Kemmyn users. He argues that this points to a situation where "the more one studies and becomes involved in Kernewek Kemmyn, the more likely one is to Kernowise one's name" (Harasta 2013: 196). While Kernewek Kemmyn was the most numerically widespread variety of Cornish at the time of Harasta's research, rendering this statistic potentially unremarkable, it can be noted that this tendency nonetheless does conform to attributes typically associated with Kernewek Kemmyn and its users.

In its lexicon, Kernewek Kemmyn favours Celtic-based neologisms and Breton borrowings over English loan words; Unified and Modern Cornish, on the other hand, take a more relaxed approach to English lexical loans, particularly when they are attested in traditional Cornish. Orthographically, too, Kernewek Kemmyn is the most distinct from English (see section 3.2). These features reflect an eagerness on the part of Kernewek Kemmyn's promoters to avoid the influence of English dominance, instead inscribing the language within a paradigm of Celticity; the fact that the Cornish name of this variety tends to be used even in English-language contexts also contributes to this prioritisation of Cornish and Celtic over English. With this in mind, it is unsurprising that Kernewek Kemmyn users appear to be the most susceptible to Kernowising their names: the process can be seen as an extension of this desire to avoid using English in a Cornish context. Indeed, in cases where speakers use these Kernowised names in their everyday, largely anglophone, life, the use of Cornish in preference to English consequently occurs even within normally monolingual English contexts, in the same way that it results from the use of the term Kernewek Kemmyn in English. In keeping with such speakers' use of the variety of Cornish that promotes the most Celtic and least English-influenced form of the language, their names are the most likely to reflect this ideology.

Kernowisation can be recognised in other cases unrelated to personal names, where Cornish is again used in contexts in which it would not usually be expected, perhaps with the aim of compensating for the dominance of English elsewhere. The Cornish Language Board (see table 1) frequently refers to itself as the Kesva even in English-language documents (e.g. Brown, Chubb, Chubb, Kennedy and Ninnis 1991: 8); it, too, is an organisation that supports Kernewek Kemmyn. As noted above, some organisations do not even have official English names, forcing the use of a Cornish name in an otherwise English-language context. Among these organisations is Agan Tavas, which promotes not Kernewek Kemmyn but Unified Cornish. This practice is widespread not only in the case of Cornish organisations but also among other Celtic languages, such as the Breton-medium Diwan schools or cultural associations such as Kevre Breizh, and organisations promoting Irish including Foras na Gaeilge and the Oireachtas. 
However, one case that seems especially widespread with regard to Cornish $^{13}$ is that of the word Cornish itself. Users of the Facebook group "I pledge to become more fluent in Cornish" ${ }^{\text {, }}$, the main location of social media activity in and relating to Cornish with nearly 900 members as of mid-2017, have produced abundant examples of posts written in English but using the Cornish word Kernewek rather than Cornish:

I'm trying on and off to learn Kernewek in Ostralie [sic] - not many speakers here. (posted 7 February 2012)

Loosely following on from ... points raised in my previous post, when is a language no longer considered to be in revival and where is Kernewek in this process? (posted 20 September 2012)

I think if kids learn Kernewek in schools or [are] just given the choice to learn it would give them a better stance [sic] of self recognition of there [sic] heritage. (posted 5 November 2013)

I am a crafter who is seeking to learn Kernewek! (posted 2 December 2015)

There are very few $<\mathrm{skr}->$ word[s] in Kernewek and most are from English - you can't just drop the $/ \mathrm{r} /$ to make a Dialect/Kernewek link. (posted 19 January 2016)

If I'm going to use a [C]eltic language to name them, I'd rather use Kernewek. (posted 2 February 2016)

Outrage As Tory Government Ends Funding For Kernewek (posted 22 April 2016)

Here's a reply from Sheryll Murray [Member of Parliament for South East Cornwall] in my email I also asked if she would be interested in meeting some Kernewek speakers, she obviously doesn't [sic] (posted 30 April 2016)

The use of Kernewek in English contexts has also, on rare occasions, occurred in academic work: Harasta (2013: 1) claims that his use of Kernewek is an act of legitimation of the language's identity, stating that he "will choose to use the term 'Kernewek' to describe the language while writing in English ... to respectfully mark it as a language with the right to name itself'. Recently,

13 This is not exclusive to Cornish - see, for example, the use of "Gaelic/An Ghàidhlig" as a section header by Ó Néill (2002:361) - but, as the examples in this paper show, is particularly widespread in Cornish across a number of domains.

14 Available at https://www.facebook.com/groups/245714002161986/, accessed 24 May 2016. The eight quotations following this paragraph are taken from this webpage. 
Kernewek was additionally used in the British newspaper The Guardian, in an article about a new television advertisement in Cornish:

The 30-second ad, which features a Cornish ice cream seller speaking the ancient Kernewek language while he sells his product, launches on Monday and will run for six weeks in programmes including Channel 4's Food Unwrapped and ITV's Britain's Got Talent ${ }^{15}$.

In this case, the term Kernewek is paired with ancient, a term that again emphasises the language's claim to legitimacy in its reference to a longstanding historical foundation. The use of Kernewek in an English context as an act of legitimation, however, raises certain problems: in an English-language text, it can easily be identified as foreign, creating a potential source of ridicule, given that its appearance, for non-speakers, is odd, and its pronunciation barely fathomable. While using Cornish would reinforce the fact that this is an established noun in the English language, signifying a specific semantic category already known to English speakers, using Kernewek does not carry this advantage, instead pointing to something unknown and far removed from the anglophone semantic sphere. Among Cornish language activists, however, these potential disadvantages seem not to have been acknowledged: the frequent use of Kernewek within their own circles seems instead to be considered to confer a greater sense of legitimacy on the language and establish its ownership by its own speakers.

\section{Delegitimisation}

As names can be used to legitimise, so can they be used to delegitimise. Supporters of particular varieties of Cornish can deliberately refuse to use the names given to rival varieties in order to undermine them. Kernewek Kemmyn, for example, has been deliberately misspelt in publications written by those who lean more towards Unified Cornish and related varieties: Williams (2006: 26) declares that "I believe that Kernowek Kemyn is not Cornish and am very unhappy that it was ever proposed or promoted", spelling the name of Kernewek Kemmyn using a specific set of Unified Cornish-based conventions, even though he is writing in English, not Cornish. Likewise, other opponents of Kernewek Kemmyn have refused to comply with the 'Kernowised' names of its users: Gendall (2007: 4) writes of "Julian Holmes, Graham Sandercock and William Brown", choosing not to use the Cornish names (Julyan and Wella) adopted by the first and third of these people.

15 Available at http://www.theguardian.com/media/2016/may/20/first-cornish-tv-ad-to-airweeks-after-language-funding-is-axed, accessed 24 May 2016. 
Similar strategies have been directed towards Modern Cornish, which users of other varieties have typically preferred to call Late Cornish. George (1995: 105) claims that this is due to the term modern causing "potential confusion" with revived Cornish as a whole, i.e. the various types of Cornish used in 'modern' society. He also asserts that "the best name for the last phase of the historical language (1575-1800) is Late Cornish, in which the word late means both tardy (le cornique tardif in French) and deceased" (George 1995: 105). Users of Modern Cornish are unlikely to want to identify the era of traditional Cornish on which their variety is based with these clearly negative descriptors.

\section{Conclusion}

Having surveyed a number of types of name used in the Cornish language revival, and the way in which these names are employed, we have seen that giving and using names both contribute to constructing and situating the Cornish identity, as well as to legitimating that identity, emphasising the importance of membership of the minority group and reinforcing the notion that the meanings of names are "crucially tied to a group membership, and to experience in a particular community" (Rymes 1996: 257-258). The distinctness of Cornish from English, and of Cornishness from Englishness, tends to be emphasised, both through the phenomenon of Kernowisation, including the use of the term Kernewek and other Cornish names in English-language contexts, and through the use of names derived from or reminiscent of Breton and Welsh; this equally locates Cornish, and the Cornish identity, within a Celtic context, seeking to overcome concerns about the apparently weaker validity of the Cornish claim to a Celtic identity highlighted by Kennedy (2013). As well as this legitimation of the language as a whole, we can identify acts of naming that contribute to the legitimation or delegitimisation of particular varieties. While all Cornish language activists by definition promote the use of the language, they exhibit varying opinions regarding which form of it should prevail. The ideologies within the Cornish language movement, reflected in the use of different varieties, can therefore be seen to fall on a broad spectrum; users of Cornish do not form a homogeneous mass, but have a range of beliefs about what Cornish should be and how it should be used, not all of which are compatible.

The drive for legitimacy helps Cornish speakers progress towards their goal of state support, funding and recognition for the language, increasing both its visibility and the number of potential speakers. After a period of relative stability for the language in terms of institutional support, the withdrawal of state funding and the reorganisation of language planning authorities have once again made the future uncertain. Examining the development of trends in the 
use of names in the Cornish revival will help illustrate the way in which Cornish speakers react to such changes, and provide guidance on how the limited support available should be deployed as the years progress in order to sustain the variety of ideologies that underpin the movement.

\section{REFERENCES}

Amery, Rob and Georgina Yambo Williams. 2009. "Reclaiming through renaming: The reinstatement of Kaurna toponyms in Adelaide and the Adelaide Plains", in: Louise Hercus, Flavia Hodges and Jane Simpson (eds.). The land is a map: Placenames of indigenous origin in Australia. Canberra: ANU Press, 255-276.

Brown, Wella. 1987. "Deryvas a'n cuntellas a vern synsys dhe'n 13 ves a vys Metheven yn kever lytherennans", An Gannas 127, 2-3.

Brown, Wella, Denise Chubb, Ray Chubb, Neil Kennedy and Jane Ninnis. 1991. The Cornish language. Unpublished report.

Combellack, Myrna. 1978. “Twelve years' progress in Unified Cornish, 1967 to 1979”, Cornish Studies 6, 45-51.

Ferdinand, Siarl. 2013. "A brief history of the Cornish language, its revival and current status", Journal of Interdisciplinary Celtic Studies 2, 199-227.

Gendall, Richard. 1988. Laugh and learn traditional Cornish through cartoons and cassette: A new course in Cornish for the beginner. Menheniot: Teere ha Tavaz.

Gendall, Richard. 2000. Tavas a ragadazow: The language of my forefathers. Menheniot: Teer ha Tavas.

Gendall, Richard. 2007. The course of true love: A view over the battlefield of revived Cornish. Unpublished paper.

George, Ken. 1986. The pronunciation and spelling of revived Cornish. Penzance: Cornish Language Board.

George, Ken. 1993. Gerlyver Kernewek Kemmyn: An gerlyver meur. Penzance: Cornish Language Board.

George, Ken. 1995. "Which base for revived Cornish?”, in: Philip Payton (ed.). Cornish Studies: Three. Exeter: University of Exeter Press, 104-124.

Harasta, Jesse. 2013. In search of a single voice: The politics of form, use and belief in the Kernewek language. $\mathrm{PhD}$ thesis, Syracuse University.

Kennedy, Neil. 2013. Employing Cornish cultures for community resilience. PhD thesis, University of Exeter.

Koch, John. 2003. "Celts, Britons and Gaels: Names, peoples and identities", Transactions of the Honourable Society of Cymmrodorion New Series 9, 41-56.

Mac Giolla Chríost, Diarmait. 2012. Jailtacht: The Irish language, symbolic power and political violence in Northern Ireland, 1972-2008. Cardiff: University of Wales Press.

MacKinnon, Ken. 2000. Cornish at its millennium: An independent study of the language. Dingwall: SGRÙD Research.

Nance, Robert M. 1929. Cornish for all. St Ives: Federation of Old Cornwall Societies.

Nance, Robert M. 1952. An English-Cornish dictionary. St Ives: Federation of Old Cornwall Societies. 
Ó Néill, Diarmuid. 2002. “Scottish-Gaelic (in Scotland)”, in: Diarmuid Ó Néill (ed.). Rebuilding the Celtic languages: Reversing language shift in the Celtic countries. Talybont: Y Lolfa, 338-365.

Payton, Philip J. 2000. "Cornish", in: Glanville Price (ed.). Languages in Britain and Ireland. Oxford: Blackwell, 109-119.

Price, Glanville. 1984. The languages of Britain. London: Edward Arnold.

Rose-Redwood, Reuben. 2016. "'Reclaim, rename, reoccupy': Decolonising place and the reclaiming of PKOLS”, ACME: An International Journal for Critical Geographies 15(1), 187-206.

Rymes, Betsy R. 1996. "Naming as social practice: The case of Little Creeper from Diamond Street", Language in Society 25, 237-260.

Rymes, Betsy R. 1999. "Names”, Journal of Linguistic Anthropology 9, 1-2.

Sayers, Dave. 2012. "Standardising Cornish: The politics of a new minority language", Language Problems and Language Planning 36, 99-119.

Wakelin, Martyn F. 1975. Language and history in Cornwall. Leicester: Leicester University Press.

Williams, Nicholas J. A. 2006. Writings on revived Cornish. Westport: Evertype.

\section{FIGURES}

Figure 1: Varieties of Cornish

\section{TABLES}

Table 1: Organisations 